\title{
Ultrasonically Processed WSe 2 Nanosheets Blended Bulk Heterojunction Active Layer for High-Performance Polymer Solar Cells and X-ray Detectors
}

\author{
Hailiang Liu ${ }^{1,+}$, Sajjad Hussain ${ }^{2,+}$ (D) Jehoon Lee ${ }^{1}$, Dhanasekaran Vikraman ${ }^{3, *(\mathbb{D})}$ and Jungwon Kang ${ }^{1, *(\mathbb{D})}$ \\ 1 Department of Electronics and Electrical Engineering, Dankook University, Yongin 16890, Korea; \\ liuhailiang107@gmail.com (H.L.); usyj0512@gmail.com (J.L.) \\ 2 Institute of Nano and Advanced Materials Engineering, Sejong University, Seoul 05006, Korea; \\ shussainawan@gmail.com \\ 3 Division of Electronics and Electrical Engineering, Dongguk University-Seoul, Seoul 04620, Korea \\ * Correspondence: v.j.dhanasekaran@gmail.com (D.V.); jkang@dankook.ac.kr (J.K.) \\ + Authors contributed equally.
}

Citation: Liu, H.; Hussain, S.; Lee, J.; Vikraman, D.; Kang, J. Ultrasonically Processed WSe $\mathrm{W}_{2}$ Nanosheets Blended Bulk Heterojunction Active Layer for High-Performance Polymer Solar Cells and X-ray Detectors. Materials 2021, 14, 3206. https://doi.org/ $10.3390 / \mathrm{ma} 14123206$

Academic Editor: Marko Topic

Received: 28 April 2021

Accepted: 7 June 2021

Published: 10 June 2021

Publisher's Note: MDPI stays neutral with regard to jurisdictional claims in published maps and institutional affiliations.

Copyright: (c) 2021 by the authors. Licensee MDPI, Basel, Switzerland. This article is an open access article distributed under the terms and conditions of the Creative Commons Attribution (CC BY) license (https:/ / creativecommons.org/licenses/by/ $4.0 /)$.

\begin{abstract}
Two-dimensional (2D) tungsten diselenide ( $\left.\mathrm{WSe}_{2}\right)$ has attracted considerable attention in the field of photovoltaic devices owing to its excellent structure and photoelectric properties, such as ordered 2D network structure, high electrical conductivity, and high mobility. For this test, we firstly prepared different sizes (NS1-NS3) of $\mathrm{WSe}_{2}$ nanosheets (NSs) through the ultrasonication method and characterized their structures using the field emission scanning electron microscope (FE-SEM), Raman spectroscopy, and X-ray powder diffraction. Moreover, we investigated the photovoltaic performance of polymer solar cells based on 5,7-Bis(2-ethylhexyl)benzo[1,2-c:4,5-c' $]$ dithiophene4,8-dione(PBDB-T):(6,6)-phenyl-C71 butyric acid methyl ester (PCBM) with different $\mathrm{WSe}_{2} \mathrm{NSs}_{\text {as }}$ the active layer. The fabricated PBDB-T:PCBM active layer with the addition of $\mathrm{NS}_{2} \mathrm{WSe}_{2} \mathrm{NSs}$ $(1.5 \mathrm{wt} \%)$ exhibited an improved power conversion efficiency (PCE) of $9.2 \%$, which is higher than the pure and NS1 and NS3 $\mathrm{WSe}_{2}$ blended active layer-encompassing devices. The improved PCE is attributed to the synergic enhancement of exciton dissociation and an improvement in the charge mobility through the modified active layer for polymer solar cells. Furthermore, the highest sensitivity of $2.97 \mathrm{~mA} / \mathrm{Gy} \cdot \mathrm{cm}^{2}$ was achieved for the NS2 $\mathrm{WSe}_{2} \mathrm{NSs}$ blended active layer detected by X-ray exposure over the pure polymer, and with the NS1 and NS2 $\mathrm{WSe}_{2}$ blended active layer. These results led to the use of transition metal dichalcogenide materials in polymer solar cells and X-ray detectors.
\end{abstract}

Keywords: $\mathrm{WSe}_{2}$ nanosheets; charge transport; mobility; polymer solar cell; sensitivity

\section{Introduction}

Optoelectronic devices based on organic semiconductors have received considerable attention in recent times [1]. Currently, organic semiconducting materials have been considered for a wide range of applications, such as organic solar cells [2-4], organic lightemitting diodes $[5,6]$, sensors $[7,8]$ and photodetectors $[9,10]$. This is mainly due to the excellent properties of organic semiconductor materials, such as their low cost, lightweight design, flexibility, and excellent thermal and mechanical stability [11-16]. A wide-bandgap polymer, 5,7-Bis(2-ethylhexyl)benzo[1,2-c:4,5- $\left.\mathrm{c}^{\prime}\right]$ dithiophene-4,8-dione (PBDB-T) is one of the most recognized and effective donor materials in polymer solar cells (PSC). Moreover, most organic-based semiconducting devices use a fullerene derivative phenyl-C70-butyric acid methyl ester (PCBM) as an acceptor due to its high rate of conductivity, which is combined with the photon charge conversion layer (active layer) [17-21]. Among the donor materials, PBDB-T-conjugated polymers are the most studied and well-recognized choice of material due to their unique properties, such as semicrystalline structure and high hole/electron mobility, as well as their ease of interaction with fullerene-based acceptors 
such as PCBM [22]. PBDB-T exhibits an excellent absorption coefficient and is located at the deepest level of the occupied molecular orbital (HOMO) [23,24]. For this reason, PBDB-T:PCBM is considered as the driving force for further in-depth research on organic solar cells, sensors and photodetectors.

Third-generation bulk heterojunction (BHJ) PSCs are cheaper and weigh less compared to first-generation single-crystal silicon-based solar cells and second-generation compound semiconductor-based solar cells [25-28]. However, their power conversion efficiency (PCE) is insufficient compared to that of other silicon-based devices. This is mainly due to the low mobility of polymer semiconductors, which leads to poor charge transportability [29]. The intrinsic potential of the active layer film and the number of photogenerated carriers generated by the recombination effect are limited by their thickness, which makes it difficult to achieve higher PCE. It is still a considerable challenge to fabricate high-performance $\mathrm{BHJ}$ organic solar cells with superior performance. Recently, ternary hybrid-based solar cell research works have attracted growing attention; for example, Sygletou et al. [30] demonstrated that solar cell PCE was improved by $12.5 \%$ through the doping of $\mathrm{WS}_{2}-$ AuNSs into the active layer (PCDTBT:PCBM). Elsewhere, Wu et al. [31] achieved an improved PCE by using different contents of graphene quantum dots (GQDs) for doping in the active layer of P3HT:PCBM. Finally, Ahmad et al. [32] successfully manufactured the ternary hybrid-based active layer of P3HT:PCBM:MoS 2 NSs with a PCE increment of $32.71 \%$ when compared to the performance of an active layer-encompassing device without $\mathrm{MoS}_{2}$ added. The PCE enhancements in the ternary hybrid layers are mainly due to their enriched capacity for light absorption and their harmonizing absorption of solar radiation [33,34]. In this respect, interest in ternary-based research has grown recently in order to improve the photovoltaic performance of PSCs.

X-rays have been widely used in the detection of indirect/direct methods and have a wide range of application prospects, including industrial inspection, scientific research (crystallography) and in the field of medicine [35-39]. The coupling of an indirect photodetector and a CsI (T1) scintillator is a common detection method in which the scintillator converts incidental X-rays into visible light. The visible light is then absorbed by the active layer, thereby forming an electron-hole pair to excite charge carriers [21,40]. In a recent report, an X-ray detector based on a ternary system was studied. Unlike the traditional hybrid device concept, a device based on a ternary structure can use the interaction between the organic semiconductor and the additive material to generate surplus-free carrier selection, thus creating a highly sensitive detector. For example, Thirimane et al. [41] reported a ternary hybrid detector based on an organic BHJ-bismuth oxide composite material with a sensitivity of $1712 \mu \mathrm{CmGy}^{-1} \cdot \mathrm{cm}^{-3}$ under $50 \mathrm{kV}$ soft X-rays. The organic semiconductors can be manufactured at low cost, at room temperature (over a large area of flexible/wearable substrate), and with an adaptable methodology for complex structures, which will more easily meet the requirements of commercialization.

Transition metal dichalcogenides (TMDs) are attractive semiconductors used in various electronics and optoelectronics [42,43]. TMDs are mainly composed of sandwiched metal ( $\mathrm{M}=\mathrm{Mo}, \mathrm{W}$, etc.) atoms between chalcogenide atoms (such as $\mathrm{S}, \mathrm{Se}$, or Te). They possess a unique chemical composition and unique physical properties, such as a high capacity for light absorption, a high carrier mobility, and high bandgap tunability, making them promising as complementary light absorbers and as additional-charge transport materials for high-efficiency ternary devices [44-47]. Usually, the BHJ structure is composed of a p-type polymer donor and an n-type fullerene acceptor material [48,49]. When the additives are introduced between the polymer donor and the acceptor, it enhances the exciton dissociation and charge transfer activities through interfacing characteristics. An inter-penetration of the nanostructure's transport network in the active layer can significantly improve carrier mobility. However, the key point of device performance is based on the involvement and interaction of a third component with the thin BHJ layer, which includes uncontrollable factors such as shape and size. For this reason, it is a challenging 
step to produce suitable nanomaterials with compatible morphological properties in order to maximize the performance of ternary devices.

In this work, we used a simple and convenient method to tune the sizes of $\mathrm{WSe}_{2}$ NSs by ultrasonication, and then added different concentrations of $\mathrm{WSe}_{2} \mathrm{NSs}$ to the polymer heteroatoms active layer of PBDB-T:PCBM to improve its inherent attributes. The experimental results showed that the NS2 WSe 2 NSs-suspended active layers (1.5 $\mathrm{wt} \%)$ produced an improved PCE of $9.2 \%$, which increased by $13.5 \%$ compared to the pristine polymer junction device PCE of $8.1 \%$. In addition, under the exposure of X-rays, the NS2 $\mathrm{WSe}_{2}$ NSs-incorporated (1.5 $\mathrm{wt} \%$ ) PBDB-T:PCBM active layer obtains a sensitivity level of $2.97 \mathrm{~mA} / \mathrm{Gy} \cdot \mathrm{cm}^{2}$.

\section{Experimental Section}

\subsection{Preparation of $\mathrm{WSe}_{2}$ Nanosheets}

Firstly, $1 \mathrm{~g}$ of $\mathrm{WSe}_{2}$ commercial powder was mixed with $100 \mathrm{~mL}$ of ethanol solution. The solution was then subjected to sonication at different times, such as 6,12 and $18 \mathrm{~h}$ in a sonic bath under $60 \mathrm{~W}$. Next, it was centrifuged at $8000 \mathrm{RPM}$ for $5 \mathrm{~min}$ to retain the precipitate. The collected precipitate was then kept in a vacuum-heating oven until the ethanol evaporated. Finally, the prepared $\mathrm{WSe}_{2}$ nanosheets were used for device fabrication and characterization. Based on the sonication times of 6,12 and $18 \mathrm{~h}$ for $\mathrm{WSe}_{2}$ preparation, the final products are named "NS1", "NS2", and "NS3", respectively, in the following text. The $\mathrm{WSe}_{2}$ nanosheets' ultrasonic preparation parameters are listed in Table S1 (Supplementary Materials).

\subsection{Device Fabrication}

The indium tin oxide (ITO)-patterned glass substrates were cleaned sequentially with acetone, methanol, and isopropyl alcohol for $5 \mathrm{~min}$ by sonication treatment, then dried in a vacuum oven at $100{ }^{\circ} \mathrm{C}$, before finally being exposed to UVO treatment for $15 \mathrm{~min}$. The PEDOT:PSS was spin-coated onto the cleaned ITO substrate at $3000 \mathrm{rpm}$ for $30 \mathrm{~s}$ and then annealed at $150{ }^{\circ} \mathrm{C}$ for $30 \mathrm{~min}$, resulting in a $40 \mathrm{~nm}$ thick PEDOT:PSS. For the pure active layer formation, a mixture of PBDB-T and PCBM (with a weight ratio of 2:3) was completely dissolved in chlorobenzene with a concentration of $20 \mathrm{mg} / \mathrm{mL}$, then subjected to constant stirring for $3 \mathrm{~h}$ at $60{ }^{\circ} \mathrm{C}$. Next, the prepared solution was spin-coated onto the PEDOT:PSS layer at $1100 \mathrm{rpm}$ for $30 \mathrm{~s}$, and treated by thermal annealing at $150{ }^{\circ} \mathrm{C}$ for $10 \mathrm{~min}$. To prepare the $\mathrm{WSe}_{2}$ NSs blended active layer, the selective concentration $(1,1.5$, and $2 \mathrm{wt} \%)$ of prepared WSe 2 NSs (NS1-NS3) was dissolved in isopropyl alcohol and then mixed with the chlorobenzene mixture (PBDB-T:PCBM-2:3 ratio), before being subjected to constant stirring for $3 \mathrm{~h}$ at $60^{\circ} \mathrm{C}$. The WSe $\mathrm{WS}_{2} \mathrm{NS}$ blended PBDB-T:PCBM active layer was then spin-coated onto the PEDOT:PSS layer at $1100 \mathrm{rpm}$ for $30 \mathrm{~s}$, and treated by thermal annealing at $150{ }^{\circ} \mathrm{C}$ for $10 \mathrm{~min}$ (Table S2). Finally, a $5 \mathrm{~nm}$ lithium fluoride (LiF) layer and a $120 \mathrm{~nm} \mathrm{Al}$ cathode were deposited on top of the active layer by thermal evaporation under a pressurized environment of $3 \times 10^{-7}$ torr. The fabricated device contains four cell structures with an active area of $0.04 \mathrm{~cm}^{2}$. To prevent the exposure of the fabricated detector to oxygen and humidity, it was enclosed under a glass lid in a glove box. The device fabrication scheme of a patterned ITO substrate with different active layers (PBDB-T:PCBM $(92 \mathrm{~nm}$ ) and PBDB-T:PCBM:WSe $2(89 \mathrm{~nm})$ ) is shown in Figure 1. 


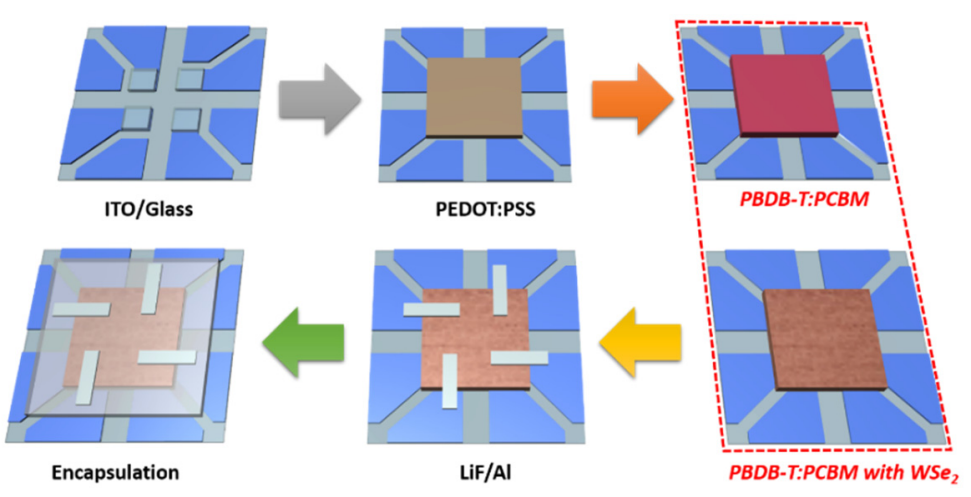

Figure 1. Schematic process for the fabrication of pure and $\mathrm{WSe}_{2}$ NSs-suspended PBDB-T:PCBM active layer comprising a $\mathrm{BHJ}$ device.

\subsection{Characterization}

Field emission scanning electron microscopy (FE-SEM, Hitachi S-4700, Tokyo, Japan) was used to describe the morphology and sizes of $\mathrm{WSe}_{2} \mathrm{NSs}$. Raman measurements were carried out using a Renishaw inVia (RE04, Gloucestershire, UK) spectrometer with a laser wavelength of $532 \mathrm{~nm}$ and an incident power of $5 \mathrm{~mW}$ for $\mathrm{WSe}_{2} \mathrm{NSs}_{\text {. The WSe }} \mathrm{NSs}$ structural characteristics were characterized using in-plane X-ray diffraction (XRD, Rigaku D/Max-2500, Tokyo, Japan) with $\mathrm{Cu}-\mathrm{K} \alpha$ radiation operated at $50 \mathrm{kV}$ and $300 \mathrm{~mA}$. Light absorption spectra were obtained using a UV-vis spectrophotometer (Optizen 2120UV, K $\mathrm{LAB}$, Daejeon, Korea) for the pure and $\mathrm{WSe}_{2}$ NSs blended PBDB-T: PCBM active layers. Atomic force microscopy (AFM) measurements were obtained for the prepared active layers using Park Systems, XE-150 (Suwon, Korea), with a non-contact operating mode. The current density-voltage $(\mathrm{J}-\mathrm{V})$ characteristics of PSCs were measured with an electrometer (Keithley 6571B, Tektronix, Inc., Beaverton, OR, USA) under the exposure of an AM 1.5Gfiltered Xe lamp with an intensity of $100 \mathrm{~mW} / \mathrm{cm}^{2}$.

The X-ray detector combined with the scintillator was characterized under X-ray exposure. The emission spectrum of the CsI(Tl) scintillator (Hamamatsu Photonics J1311, Shizuoka, Japan) was measured under X-ray irradiation with a spectrometer (AvaSpec ULS2048L, StellarNet, Inc., Tampa, FL, USA). The prepared detector was placed at a distance of $30 \mathrm{~cm}$ from the $\mathrm{X}$-ray generator, with the operation of the $\mathrm{X}$-ray generator fixed under the conditions of $80 \mathrm{kVp}$ and $60 \mathrm{~mA} \cdot \mathrm{s}$, before being irradiated for $1.57 \mathrm{~s}$. In order to collect the charge under the $\mathrm{X}$-ray exposure period, a bias voltage of $0.6 \mathrm{~V}$ between the cathode and anode of the detector was applied. In addition, at the same distance $(30 \mathrm{~cm}$ ), the X-ray exposure dose was measured using an ion chamber (Capintec CII50, Mirion Technologies (Capintec), Inc., Florham Park, NJ, USA), and the absorbed dose from exposure to the X-ray was $3.14 \mathrm{mGy}$. The radiation parameters were calculated using the following Formulas (1) and (2), which correspond to the collected current density (CCD) under X-ray irradiation conditions and the dark current density (DCD) under X-ray irradiation conditions, respectively. The sensitivity of the $\mathrm{X}$-ray detector was calculated using a Formula (3), which indicates that the current generated is proportional to the absorbed dose.

$$
\begin{gathered}
\mathrm{CCD}\left[\frac{\mu \mathrm{A}}{\mathrm{cm}^{2}}\right]=\frac{\text { Collected Current during X-ray ON }}{\text { Exposed Detection Area }} \\
\text { DCD }\left[\frac{\mu \mathrm{A}}{\mathrm{cm}^{2}}\right]=\frac{\text { Collected Current during X-ray OFF }}{\text { Exposed Detection Area }} \\
\text { Sensitivity }\left[\frac{\mu \mathrm{A}}{\mathrm{mGy} \cdot \mathrm{cm}^{2}}\right]=\frac{\mathrm{CCD}-\mathrm{DCD}}{\text { Absorbed Dose }}
\end{gathered}
$$




\section{Results and Discussion}

The morphological characteristics of different $\mathrm{WSe}_{2}$ NSs were evaluated by FE-SEM measurements. Figure 2a-c show the FE-SEM images of NS1, NS2 and NS3 WSe ${ }_{2}$, respectively. The prepared NS1 WSe 2 produces the agglomerated larger-size granular structure with inhomogeneous shapes and sizes. Moreover, the observed surface reveals the voids and hillocks of a natured morphology. The sizes of the grains were estimated using line profiling with FE-SEM. The line profile of Figure $2 \mathrm{~d}$ reveals NS1 WSe $\mathrm{NSs}_{2}$ with an average size of $\sim 80 \mathrm{~nm}$. Agglomerated grain bunches made of nano-sized grains are observed for NS2 $\mathrm{WSe}_{2}$ (Figure 2b). Furthermore, a line profile (Figure 2e) of NS2 WSe 2 explores the $\sim 50 \mathrm{~nm}$ diameter of average grain sizes. For NS3 $\mathrm{WSe}_{2}$, the fragmented sizes of differently shaped grains are shown in Figure $2 \mathrm{c}$ and its line profile (Figure $2 \mathrm{f}$ ) indicates minimized sizes of grains with a $\sim 30 \mathrm{~nm}$ average diameter. The observed results prove that the sizes of $\mathrm{WSe}_{2} \mathrm{NSs}$ grains are purely affected by the time of ultrasonic treatment due to the dispersion of nanosheets during the ultrasonic treatment [50].

(a)

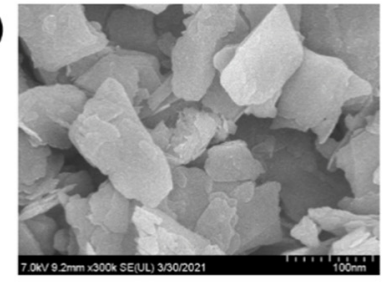

(d)

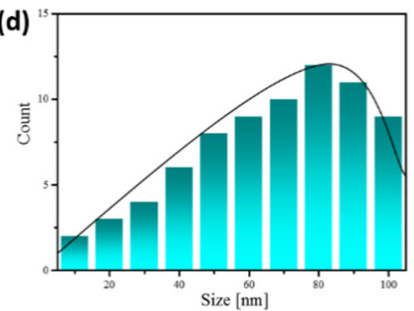

(b)

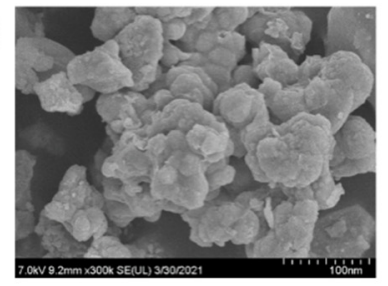

(e)

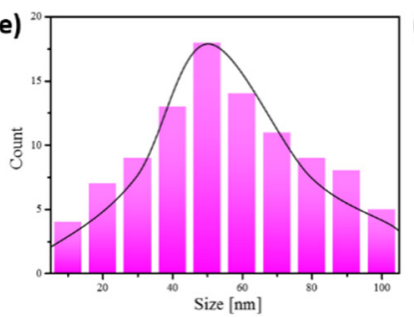

(c)

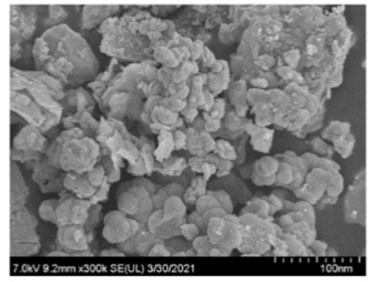

(f)

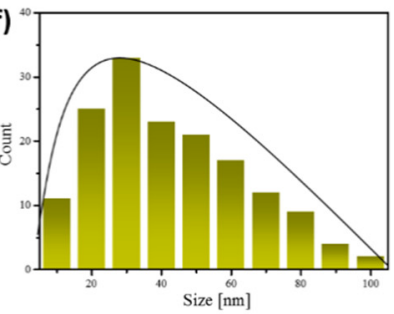

Figure 2. SEM images of WSe 2 NSs (a) NS1 (6 h sonication), (b) NS2 (12 h sonication), and (c) NS3 (18 h sonication); (d-f) particle size distribution of WSe 2 NSs (d) NS1 (6 h sonication), (e) NS2 (12 h sonication) and (f) NS3 (18 h sonication).

The structural property of NS1-NS3 $\mathrm{WSe}_{2}$ was characterized using Raman scattering analysis. Figure 3 a shows the Raman scattering profiles of $\mathrm{WSe}_{2} \mathrm{NSs}$. The Raman scattering of NS1 displays two distinct characteristic peaks of $\mathrm{E}_{2 \mathrm{~g}}$ mode and $\mathrm{E}_{1 \mathrm{~g}}$ mode, located at $173.99 \mathrm{~cm}^{-1}$ and $250.22 \mathrm{~cm}^{-1}$, respectively [51,52]. For the NS2 and NS3 WSe ${ }_{2}$ nanostructures, the peak positions are kept constant but their peak intensities are considerably altered. In our observation, the Raman peak intensities reduced considerably after an increase in ultrasonic treatment. The layered structure of $\mathrm{WSe}_{2}$ bonded with weak Van der Waals forces between their layers. During the longer ultrasonic bath, weak forces collapsed and induced the agglomeration of the bulk nature of $\mathrm{WSe}_{2}$ [53]. In addition, due to the dispersion of the layered structure and nano-sheet sizes, the Raman phonon modes either significantly broadened or were strongly suppressed [52]. These agglomeration characteristics and size decrements are clearly portrayed in the Raman signals. The crystalline nature of NS1-NS3 $\mathrm{WSe}_{2}$ was characterized by XRD analysis. Figure $3 \mathrm{~b}$ reveals the diffraction peaks of $\mathrm{WSe}_{2}$ located at $13.28^{\circ}$ and $32.05^{\circ}$ corresponding to the (002) and (100) lattice planes, respectively. The (002) peak intensity is significantly reduced, while the (100) plane intensity is considerably greater with an increase in sonication time [54,55]. The d-spacing of the (002) peak ascribes the single layer thickness of $\mathrm{WSe}_{2}$. After the lengthiest sonication of $18 \mathrm{~h}$, the reduction in (002) peak intensity suggests the destacking/termination of the $\mathrm{WSe}_{2}$ layered architecture. The observed results are consistent with the Raman observation. However, unrelated layers randomly folded between other layers, resulting in an increase 
in (100) lattice-plane peak intensity. The observed results decoded the role of sonication time to produce the highly active $\mathrm{WSe}_{2}$ NSs.
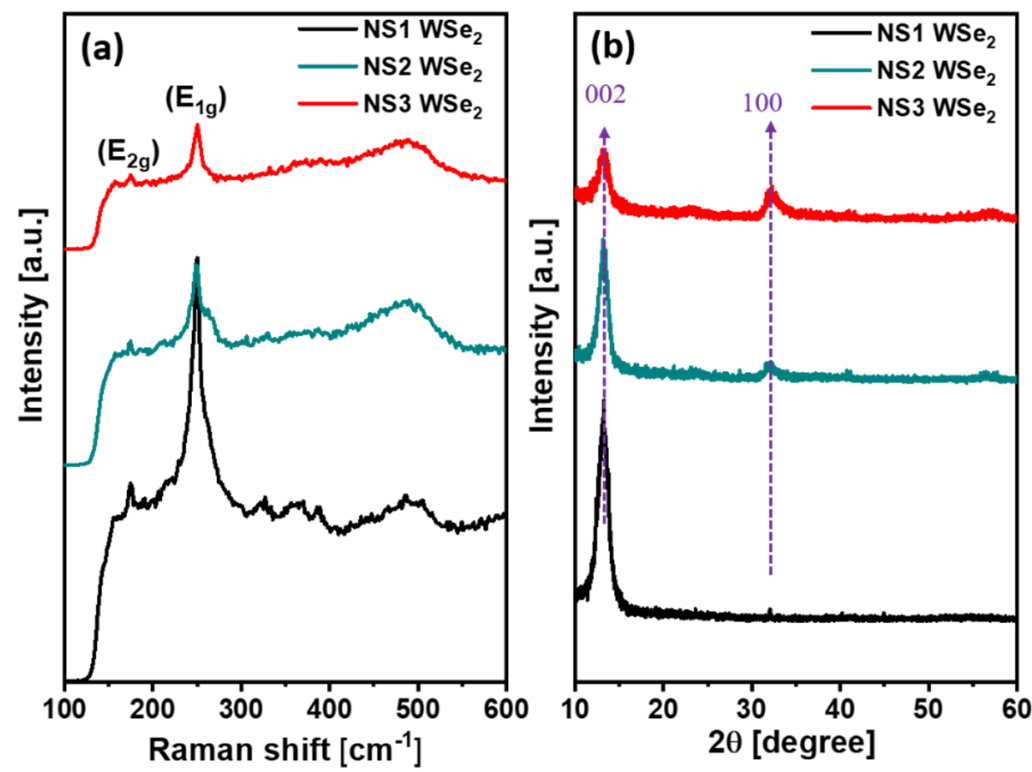

Figure 3. (a) Raman spectra and (b) XRD patterns of NS1-NS3 $\mathrm{WSe}_{2} \mathrm{NSs}_{\text {. }}$

The effect of incorporation of different $\mathrm{WSe}_{2}$ NSs with the PBDB-T:PCBM active layer on the optical properties was investigated by ultraviolet-visible absorption spectroscopy. Figure 4a shows the absorption spectra of pure and NS1-NS3 $\mathrm{WSe}_{2}$ NSs blended PBDBT:PCBM film. The pristine PBDB-T:PCBM film's absorption spectrum displays several characteristic features with the three distinct peaks at 474, 580 and $632 \mathrm{~nm}$. An observed weak peak centered at $474 \mathrm{~nm}$ is associated with the absorption following the extended conjugation of PCBM in the solid state, and the doublets at 580 and $632 \mathrm{~nm}$ attribute to the interchain vibrational absorption of ordered PBDB-T chains. Compared to the pristine PBDB-T:PCBM, the PBDB-T:PCBM:WSe 2 hybrid displays an enhancement in the absorption profile for different NS1-NS3 $\mathrm{WSe}_{2}(1.5 \mathrm{wt} \%)$, as shown in Figure $4 \mathrm{a}$. Furthermore, the different concentrations, such as $1,1.5$ and $2 \mathrm{wt} \%$, of NS2 $\mathrm{WSe}_{2}$ NSs blended PBDB-T:PCBM films' absorption profiles are shown in Figure $4 b$, which depicts a high absorption behavior for the $1.5 \mathrm{wt} \% \mathrm{NS} 2 \mathrm{WSe}_{2}$. The addition of $\mathrm{WSe}_{2} \mathrm{NSs}$ with the PBDB-T:PCBM active layer provides a superior photon transmission path and enhances photon absorption characteristics.

The impact of the incorporation of $\mathrm{WSe}_{2} \mathrm{NSs}$ with an active layer on the photovoltaic and photodetector performances of ITO/PEDOT:PSS/PBDB-T:PCBM:WSe $2 / \mathrm{LiF} / \mathrm{Al}$ device was measured by current density-voltage $(\mathrm{J}-\mathrm{V})$ characteristics. The schematic of the hybrid polymer solar cell's structure and the X-ray detector's structure is shown in Figure 5a,b, respectively. Figure $5 \mathrm{c}$ shows the energy level diagram of each component used for the fabrication of the device. For the X-ray detector, the CsI(Tl) scintillator was constructed, which consisted of $400 \mu \mathrm{m}$ thick CsI and $0.5 \mathrm{~mm}$ thick Al. The induced X-ray photons were converted through the scintillator, and were then absorbed by the active layer (PBDBT:PCBM:WSe ${ }_{2}$ NSs) to create electron-hole pairs. The transfer of electrons/holes through the cathode/anode thus collected charges. According to the energy band position, additive $\mathrm{WSe}_{2}$ NSs help the movement of electrons from PCBM to the cathode, whereas the hole transport layer (HTL) of PEDOT:PSS helps the movement of holes towards the anode. 

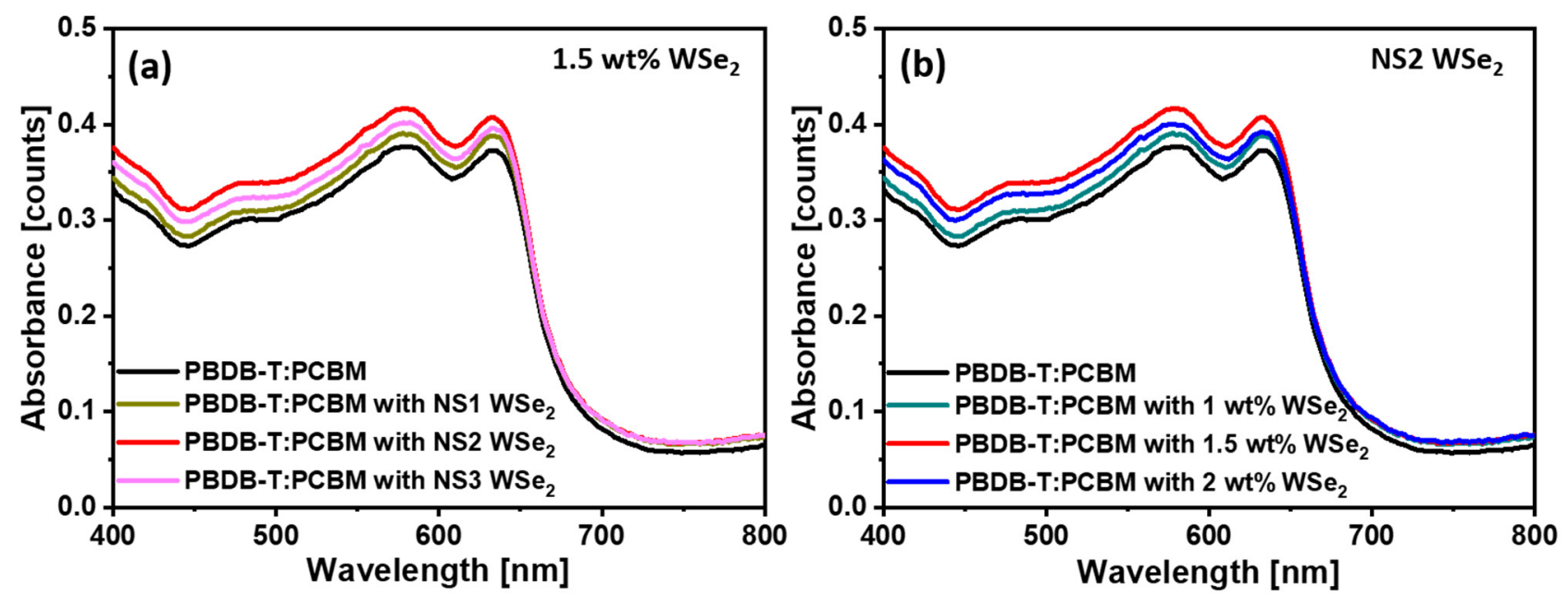

Figure 4. (a) UV-vis absorption spectra of pure and NS1-NS3 WSe ${ }_{2}$ NSs blended PBDB-T:PCBM film; (b) UV-vis absorption spectra of pure and different concentrations of NS2 $\mathrm{WSe}_{2}$ blended PBDB-T:PCBM film.

(a)

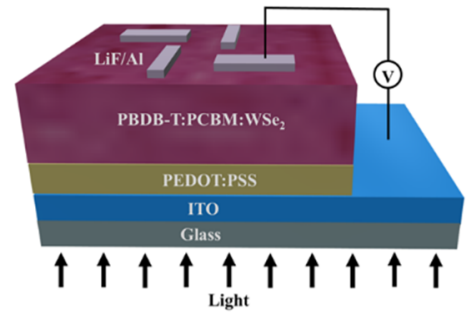

(b)
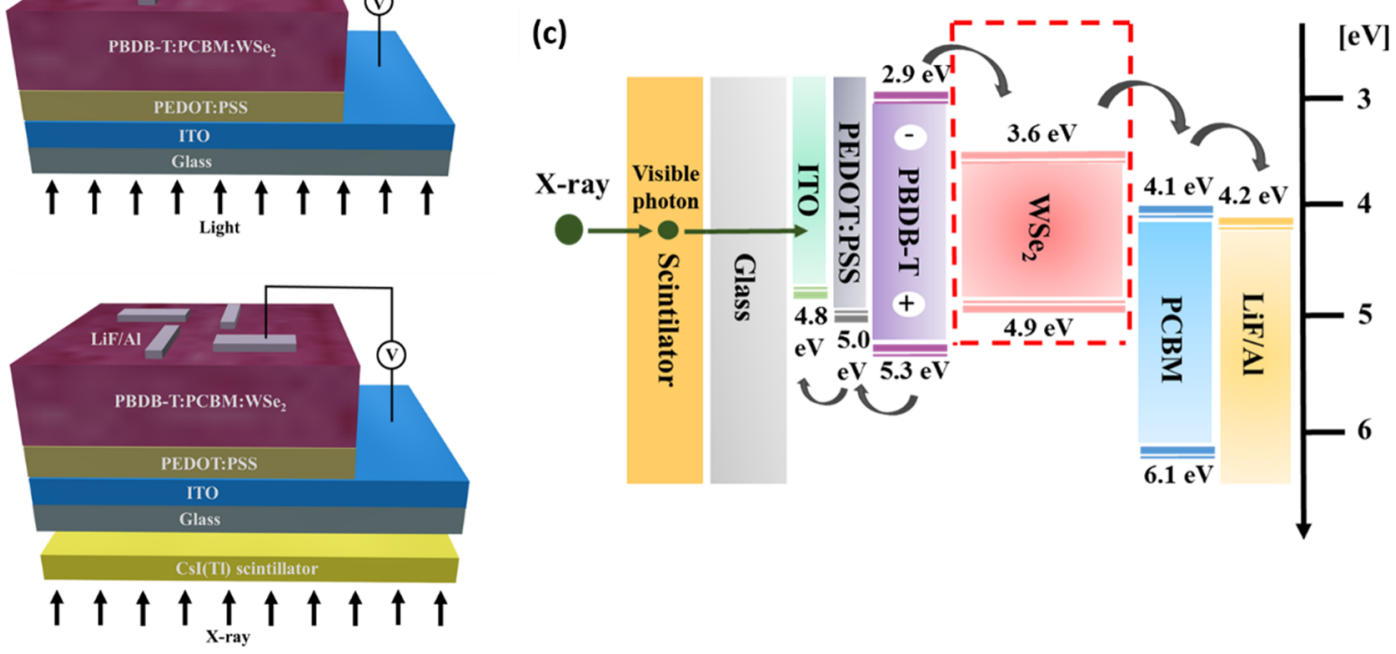

Figure 5. Schematic illustration of (a) hybrid polymer solar cell structure; (b) X-ray detector structure combined with ScI(Tl) scintillator; (c) energy level diagram of the device.

To explore the photovoltaic behavior, the J-V characteristics of pristine PBDB-T:PCBM and $\mathrm{WSe}_{2}$ NSs-incorporated PBDB-T:PCBM devices were measured under AM 1.5 G conditions at an illumination intensity of $100 \mathrm{~mW} / \mathrm{cm}^{2}$. Figure 6 a shows the $\mathrm{J}-\mathrm{V}$ characteristics of devices comprising pure and NS1-NS3 WSe 2 NSs (1.5 wt\%)-incorporated PBDB-T:PCBM active layers. Using a PSC device, we showed that the pristine PBDB-T:PCBM active layer displayed a short-circuit current density (Jsc) of $16.81 \mathrm{~mA} \cdot \mathrm{cm}^{2}$ and an open-circuit voltage (Voc) $0.84 \mathrm{~V}$, with a fill factor (FF) of $56 \%$ and series resistance (Rs) of $225.43 \Omega \cdot \mathrm{cm}^{2}$, resulting in a PCE of $8.1 \%$. After the incorporation of different NS1-NS3 WSe 2 NSs, the performances of the PSC devices were considerably improved. Further, the observed PSC outcomes are provided in Table 1. After the incorporation of $\mathrm{WSe}_{2} \mathrm{NSs}$ into the active layer, the light-absorption capacity of the composite films significantly improved compared to the pristine device, which promoted the exciton generation rate. The results reveal that the device with the NS2 (1.5 wt \%) WSe $\mathrm{WSs}_{2}$ active layer produces the highest $\mathrm{J}_{\mathrm{SC}}$ of $19.78 \mathrm{~mA} / \mathrm{cm}^{2}, \mathrm{~V}_{\mathrm{OC}}$ of $0.85 \mathrm{~V}$, Rs of $122.02 \Omega \cdot \mathrm{cm}^{2}$ and FF of $55 \%$, with a very promising PCE of $9.2 \%$. The presence of $\mathrm{WSe}_{2} \mathrm{NSs}$ in the ternary blend provides an additional PBDB-T:PCBM:WSe 2 interface, thus inducing a large interfacial area for charge separation, and it thereby accelerates the rate of exciton dissociation. Moreover, the highly 
conductive 2D network of NS2 WSe 2 NSs offers new interconnected percolation networks for charge-carrier transport and collection, which could improve the electron mobility, resulting in larger JSC. The observed low Rs further establishes the improved solar cell performances for $\mathrm{WSe}_{2}$-incorporating active layers. The observed values are provided with standard deviation (Table 1) between their five replicated experiments to prove their stable performances. Similarly, the J-V characteristics of the constructed devices using different concentrations, such as 1, 1.5 and $2 \mathrm{wt} \%$, of NS2 $\mathrm{WSe}_{2}$ blended PBDB-T:PCBM:WSe $\mathrm{W}_{2}$ in their active layer are provided in Figure $6 \mathrm{~b}$. The observed results clearly illustrate the improved behavior of the $1.5 \mathrm{wt} \%$ blended active layers. The detailed PSC parameters are presented in the Table 2. In addition, in order to realize the role of concentration variation in achieving high performance, AFM measurements were performed to study the topography of the active layer prepared on ITO-coated glass. Figure S1 shows the 3D AFM topographical images of pure and different concentrations (1, 1.5 and $2 \mathrm{wt} \%$ ) of the NS2 $\mathrm{WSe}_{2}$-doped PBDB-T:PCBM heterojunction active layer. The RMS surface roughness of the active layer is $1.73 \mathrm{~nm}, 1.59 \mathrm{~nm}, 1.49 \mathrm{~nm}$ and $1.53 \mathrm{~nm}$ for the pure and 1, 1.5 and $2 \mathrm{wt} \% \mathrm{NS} 2 \mathrm{WSe}_{2}$-doped PBDB-T:PCBM active layers, respectively. The development of a very dense PCDTB-T:PCBM:WSe ${ }_{2}$ NS2 $(1.5 \mathrm{wt} \%)$ active layer could prevent the leakage of current and produce conduits useful for charge conveyance and separation, improving the device's performance [56]. Further, to validate the performances of the devices with different concentrations $\left(1,1.5\right.$, and $2 \mathrm{wt} \%$ ) of NS1 and NS3 $\mathrm{WSe}_{2}$ doping, PSC J-V profiles are provided in Figures S2 and S3, respectively.
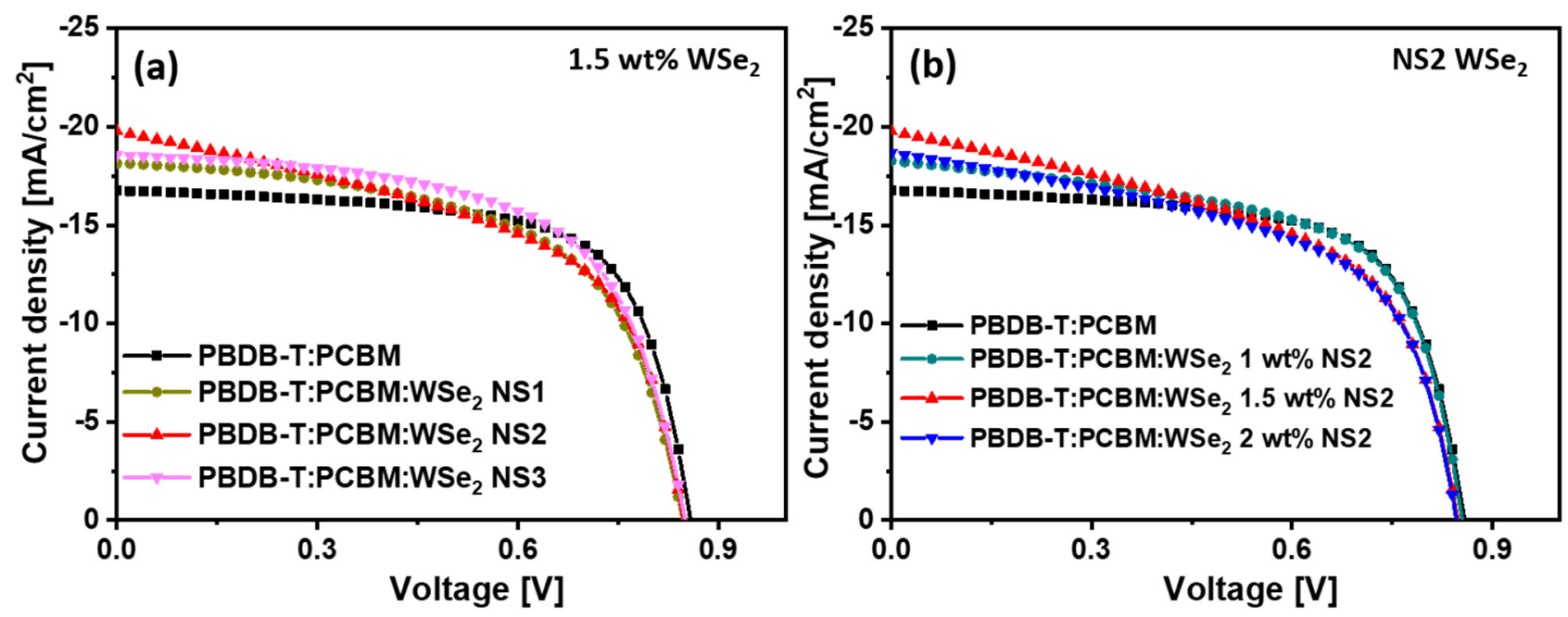

Figure 6. J-V characteristics: (a) pristine and different $\mathrm{WS}_{2}$ NSs blended PBDB-T:PCBM active layers; (b) pristine and different amounts of NS2 WSe 2 NSs blended into the PBDB-T:PCBM active layer.

The fabricated X-ray detectors were measured using the X-ray generator and electrometer, as described in the experimental part. Figure 7a shows the logarithmic J-V characteristics of pure and NS1-NS3 WSe 2 NSs (1.5 wt \%) blended PBDB-T:PCBM active layers using prepared detectors. For the pristine PBDB-T:PCBM active layer, the $\mathrm{X}$-ray detector achieves a $2.55 \mathrm{~mA} / \mathrm{Gy} \cdot \mathrm{cm}^{2}$ sensitivity. When the active layer is blended with NS1-NS3 WSe ${ }_{2}$ NSs, the sensitivity is increased to $2.63,2.97$, and $2.76 \mathrm{~mA} / \mathrm{Gy} \cdot \mathrm{cm}^{2}$ for NS1, NS2 and NS3, respectively (Figure 7b, right-side axis). The extracted CCD-DCDs (Figure 7b, left side axis) are at $8.01,8.25,9.32$, and $8.67 \mu \mathrm{A} / \mathrm{cm}^{2}$ for the pure and NS1-NS3 blended PBDB-T:PCBM active layers using the prepared X-ray detectors, respectively. Similarly, the outcomes of different NS2 $\mathrm{WSe}_{2}$ NSs blended PBDB-T:PCBM active layers using prepared $\mathrm{X}$-ray detectors are provided in Figure $7 \mathrm{c}$. The sensitivity as assessed by $\mathrm{X}$-ray realizes gives values of $2.55,2.74,2.97$, and $2.86 \mathrm{~mA} / \mathrm{Gy} \cdot \mathrm{cm}^{2}$ for the pristine PBDB-T:PCBM active layer and $1 \mathrm{wt} \%, 1.5 \mathrm{wt} \%$ and $2 \mathrm{wt} \%$ NS2 WSe $\mathrm{WSs}_{2}$, respectively (as shown in Figure $7 \mathrm{c}$, right-side axis). The estimated CCD-DCD values are $8.01,8.60,9.32$, and $8.98 \mu \mathrm{A} / \mathrm{cm}^{2}$ for 
the pristine PBDB-T:PCBM active layer and $1 \mathrm{wt} \%, 1.5 \mathrm{wt} \%$ and $2 \mathrm{wt} \% \mathrm{NS} 2 \mathrm{WSe}_{2} \mathrm{NSs}$, respectively. The observed X-ray detector outcomes for NS1 and NS3 WSe $\mathrm{N}_{2} \mathrm{NSs}(1,1.5$, and $2 \mathrm{wt} \%$ ) blended PBDB-T:PCBM active layers are provided in Figures S3 and S4, respectively. Better outcomes are ensured for the $1.5 \mathrm{wt} \%$ NS2 $\mathrm{WSe}_{2}$ NSs hybrid active layer under $\mathrm{X}$-ray detection due to the enhanced conductivity, improved light absorption capacity, and superior mobility.

Table 1. PSC performances of pristine and different $\mathrm{WSe}_{2}$ NSs blended PBDB-T:PCBM active layers using constructed devices ( \pm indicates the standard deviation).

\begin{tabular}{ccccccc}
\hline WSe $_{2}$ Type & Doping wt $\mathbf{~}$ & Voc $(\mathrm{V})$ & JsC $\left(\mathbf{m A} / \mathbf{c m}^{\mathbf{2}}\right)$ & FF (\%) & PCE $(\mathbf{\%})$ & Rs $\left(\mathbf{\Omega} \cdot \mathbf{c m}^{\mathbf{2}}\right)$ \\
\hline- & 0 (Pure) & $0.84 \pm 0.01$ & $16.81 \pm 0.13$ & $56 \pm 1$ & $8.1 \pm 0.09$ & $225.43 \pm 2.78$ \\
\hline NS1 & 1.5 & $0.84 \pm 0.01$ & $18.14 \pm 0.17$ & $54 \pm 1$ & $8.4 \pm 0.14$ & $144.38 \pm 3.15$ \\
\hline NS2 & 1.5 & $0.85 \pm 0.01$ & $19.78 \pm 0.19$ & $55 \pm 1$ & $9.2 \pm 0.17$ & $122.02 \pm 4.76$ \\
\hline NS3 & 1.5 & $0.85 \pm 0.01$ & $18.56 \pm 0.18$ & $55 \pm 1$ & $8.7 \pm 0.15$ & $136.81 \pm 3.59$ \\
\hline
\end{tabular}

Table 2. PSC performances of pristine and different amounts NS2 WSe 2 NSs blended into the PBDB-T:PCBM active layer using constructed devices ( \pm indicates the standard deviation).

\begin{tabular}{|c|c|c|c|c|c|}
\hline NS2 $W_{S e}(w t \%)$ & $\operatorname{Voc}(\mathrm{V})$ & $\mathrm{J}_{\mathrm{SC}}\left(\mathrm{mA} / \mathrm{cm}^{2}\right)$ & FF (\%) & PCE (\%) & $\operatorname{Rs}\left(\Omega \cdot \mathrm{cm}^{2}\right)$ \\
\hline 0 (Pure) & $0.84 \pm 0.01$ & $16.81 \pm 0.13$ & $56 \pm 1$ & $8.1 \pm 0.09$ & $225.43 \pm 2.78$ \\
\hline 1 & $0.85 \pm 0.01$ & $18.27 \pm 0.17$ & $55 \pm 1$ & $8.6 \pm 0.15$ & $157.33 \pm 3.42$ \\
\hline 1.5 & $0.85 \pm 0.01$ & $19.78 \pm 0.19$ & $55 \pm 1$ & $9.2 \pm 0.17$ & $122.02 \pm 4.76$ \\
\hline 2 & $0.85 \pm 0.01$ & $18.69 \pm 0.18$ & $56 \pm 1$ & $8.9 \pm 0.16$ & $126.13 \pm 3.85$ \\
\hline
\end{tabular}
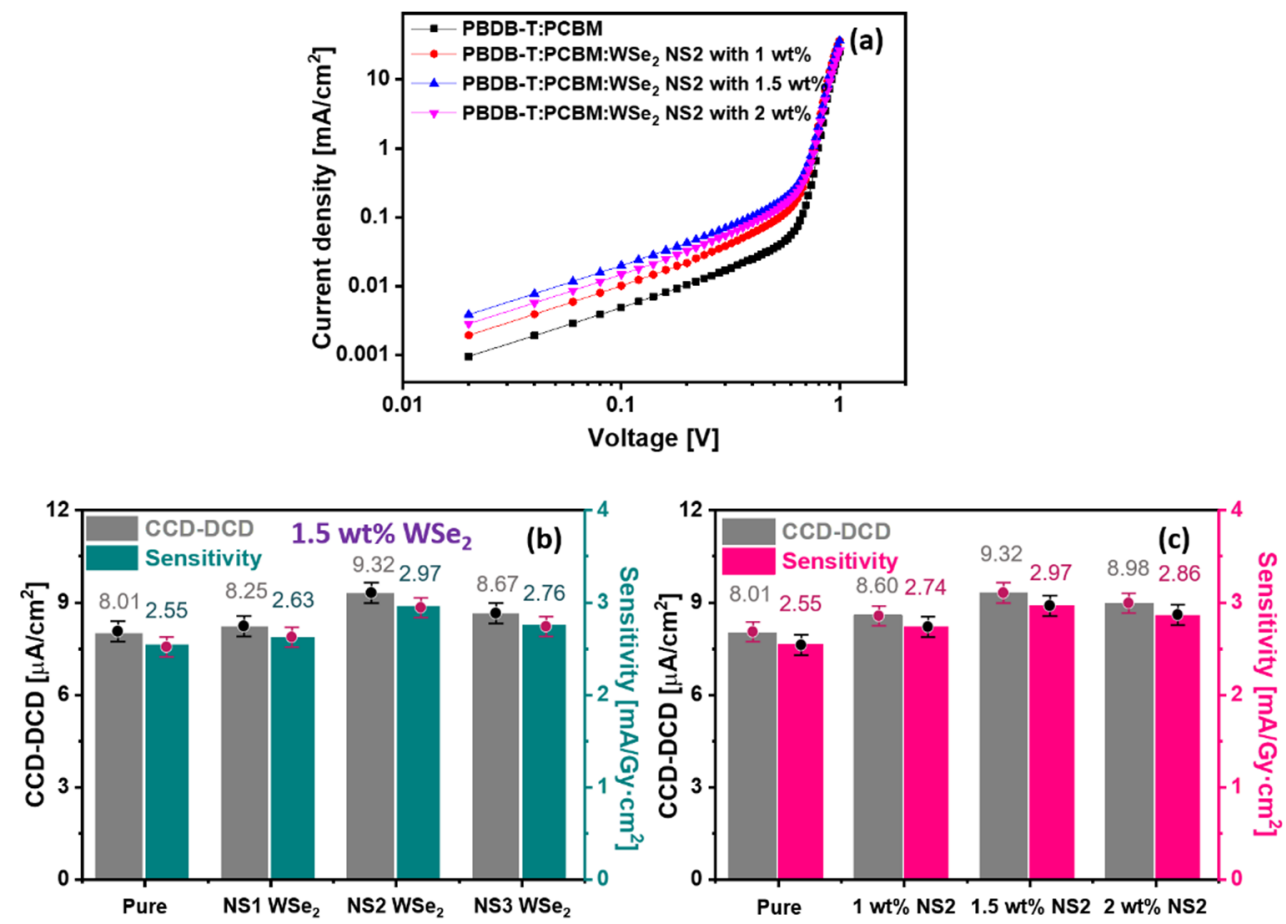

Figure 7. (a) Log J-V characteristics and (b) CCD-DCD and sensitivity variations (with the standard deviation error bar) Figure S1. NS3 WSe2 NSs blended PBDB-T:PCBM active layers as assessed by X-ray detectors; (c) CCD-DCD and sensitivity variations (with the standard deviation error bar) for pure and different concentration of NS2 WSe2 NSs blended PBDB-T:PCBM active layers assessed via X-ray detectors. 
The carrier mobility was determined using the space-charge-limited-current (SCLC) method in the dark, and it was obtained using the modified Mott-Gurney equation as shown below:

$$
\mu=\frac{8}{9} \times J \times \frac{L^{3}}{V_{a}^{2} \times \varepsilon_{0} \times \varepsilon_{r}}
$$

where $\varepsilon_{0}$ is the permittivity of free space $\left(=8.85 \times 10^{-12} \mathrm{~F} \cdot \mathrm{m}^{-1}\right), \varepsilon_{r}$ is the relative permittivity of the active layer, $V_{a}$ is the voltage applied across the detector, $\mu$ is the carrier mobility, and $L$ is the thickness of the active layer. The calculated mobilities using the detector are at $5.62 \times 10^{-5}, 5.23 \times 10^{-4}, 8.82 \times 10^{-4}$, and $7.13 \times 10^{-4} \mathrm{~cm}^{2} / \mathrm{V} \cdot \mathrm{s}$ for the pristine active layer and $1 \mathrm{wt} \%, 1.5 \mathrm{wt} \%$ and $2 \mathrm{wt} \%$ of $\mathrm{NS}_{2} \mathrm{WSe}_{2} \mathrm{NSs}$ blended active layers, respectively.

\section{Conclusions}

In this work, we have ultrasonically prepared exfoliated $\mathrm{WSe}_{2} \mathrm{NSs}$ and blended them with PBDB-T:PCBM as an active layer for ternary hybrid solar cells and X-ray detectors. The different types (NS1-NS3) of WSe ${ }_{2}$ NSs were incorporated with active layers to explore their potentials to alter the electron transport behavior in the prepared devices. The TMD $\mathrm{WSe}_{2}$ blended active layer produced a synergistic enhancement of exciton generation and dissociation, and enhanced hole and electron transport through the active layer, which helped in achieving the high $\mathrm{J}_{\mathrm{SC}}$ and PCE for solar cells and the high sensitivity of detectors. The highest PCE of 9.2\% was attained for the NS2 $\mathrm{WSe}_{2}(1.5 \mathrm{wt} \%)$ blended PBDB-T:PCBM active layer, which is higher than the devices comprised of pristine and NS1 and NS3 blended active layers. The fabricated X-ray detectors achieved the maximum CCD-DCD of $9.32 \mu \mathrm{A} / \mathrm{cm}^{2}$, a high sensitivity of $2.97 \mathrm{~mA} / \mathrm{Gy} \cdot \mathrm{cm}^{2}$, and large carrier mobility of $8.82 \times 10^{-4} \mathrm{~cm}^{2} / \mathrm{V} \cdot \mathrm{s}$ for the NS2 $\mathrm{WSe}_{2}(1.5 \mathrm{wt} \%)$ blended PBDB-T:PCBM active layer. Our research work provides a good strategy for incorporating highly dispersed aggregated $\mathrm{WSe}_{2}$ NSs in an active layer to promote the charge extraction process and electron/hole transport behavior, thus realizing high-performance semiconductor devices. These results offer a new direction for the development of high-performance devices based on hybrid structures for future electronics.

Supplementary Materials: The following are available online at https:/ / www.mdpi.com/article/10 .3390/ma14123206/s1, Table S1: Ultrasonic preparation parameters for WSe $\mathrm{W}_{2}$ nanosheets. Table S2: Active layer preparation parameters. Figure S1. Atomic force measurement (AFM) image (a) PBDBT:PCBM, (b) PBDB-T:PCBM:WSe ${ }_{2}$ NS2 with 1 wt $\%$, (c) PBDB-T:PCBM:WSe ${ }_{2}$ NS2 with 1.5 wt $\%$ and (d) PBDB-T:PCBM:WSe 2 NS2 with $2 \mathrm{wt} \%$, Figure S2: J-V characteristics and their outcomes for pristine and different amounts NS1 WSe ${ }_{2}$ NSs blended PBDB-T:PCBM active layer, Figure S3: J-V characteristics and their outcomes for pristine and different amounts NS3 $\mathrm{WSe}_{2} \mathrm{NSs}_{\text {blended PBDB-T:PCBM }}$ active layer, Figure S4: CCD-DCD and sensitivity variations for pure and different concentrations of NS1 $\mathrm{WSe}_{2}$ NSs blended PBDB-T:PCBM active layer comprised X-ray detectors, Figure S5: CCD-DCD and sensitivity variations for pure and different concentrations of NS3 $\mathrm{WSe}_{2} \mathrm{NSs}_{\text {blended PBDB- }}$ T:PCBM active layer comprised X-ray detectors, Table S3: Photovoltaic parameters of polymer/2D materials-based PSCs.

Author Contributions: Conceptualization, H.L. and S.H.; data curation, J.L.; formal analysis, H.L., S.H. and J.L.; funding acquisition, J.K.; investigation, S.H. and D.V.; methodology, H.L. and D.V.; software, J.L.; supervision, J.K.; validation, D.V.; writing-original draft, H.L. and S.H.; writingreview and editing, D.V. and J.K. All authors have read and agreed to the published version of the manuscript.

Funding: This work was supported by the National Research Foundation of Korea (NRF) grant funded by the Korea government (MSIT) (No. 2017R1A2A2A05069821).

Institutional Review Board Statement: Not applicable.

Informed Consent Statement: Not applicable.

Data Availability Statement: Data Sharing is not applicable.

Conflicts of Interest: The authors declare no conflict of interest. 


\section{References}

1. Foster, S.; Deledalle, F.; Mitani, A.; Kimura, T.; Kim, K.-B.; Okachi, T.; Kirchartz, T.; Oguma, J.; Miyake, K.; Durrant, J.R.; et al. Electron Collection as a Limit to Polymer:PCBM Solar Cell Efficiency: Effect of Blend Microstructure on Carrier Mobility and Device Performance in PTB7:PCBM. Adv. Energy Mater. 2014, 4, 1400311. [CrossRef]

2. Oh, S.H.; Heo, S.J.; Yang, J.S.; Kim, H.J. Effects of ZnO Nanoparticles on P3HT:PCBM Organic Solar Cells with DMF-Modulated PEDOT:PSS Buffer Layers. ACS Appl. Mater. Interfaces 2013, 5, 11530-11534. [CrossRef]

3. Xu, Y.; Yuan, J.; Zhou, S.; Seifrid, M.; Ying, L.; Li, B.; Huang, F.; Bazan, G.C.; Ma, W. Ambient Processable and Stable All-Polymer Organic Solar Cells. Adv. Funct. Mater. 2019, 29, 1806747. [CrossRef]

4. Lee, D.; Kim, J.; Park, G.; Bae, H.W.; An, M.; Kim, J.Y. Enhanced Operating Temperature Stability of Organic Solar Cells with Metal Oxide Hole Extraction Layer. Polymers 2020, 12, 992. [CrossRef] [PubMed]

5. Zhang, Q.; Li, B.; Huang, S.; Nomura, H.; Tanaka, H.; Adachi, C. Efficient blue organic light-emitting diodes employing thermally activated delayed fluorescence. Nat. Photon. 2014, 8, 326-332. [CrossRef]

6. Huang, T.; Jiang, W.; Duan, L. Recent progress in solution processable TADF materials for organic light-emitting diodes. J. Mater. Chem. C 2018, 6, 5577-5596. [CrossRef]

7. Torsi, L.; Magliulo, M.; Manoli, K.; Palazzo, G. Organic field-effect transistor sensors: A tutorial review. Chem. Soc. Rev. 2013, 42, 8612-8628. [CrossRef] [PubMed]

8. Lee, Y.H.; Kweon, O.Y.; Kim, H.; Yoo, J.H.; Han, S.G.; Oh, J.H. Recent advances in organic sensors for health self-monitoring systems. J. Mater. Chem. C 2018, 6, 8569-8612. [CrossRef]

9. Wang, W.; Zhang, F.; Du, M.; Li, L.; Zhang, M.; Wang, K.; Wang, Y.; Hu, B.; Fang, Y.; Huang, J. Highly Narrowband Photomultiplication Type Organic Photodetectors. Nano Lett. 2017, 17, 1995-2002. [CrossRef]

10. Yang, D.; Ma, D. Development of Organic Semiconductor Photodetectors: From Mechanism to Applications. Adv. Opt. Mater. 2019, 7, 1800522. [CrossRef]

11. Fujisaki, Y.; Koga, H.; Nakajima, Y.; Nakata, M.; Tsuji, H.; Yamamoto, T.; Kurita, T.; Nogi, M.; Shimidzu, N. Transparent Nanopaper-Based Flexible Organic Thin-Film Transistor Array. Adv. Funct. Mater. 2014, 24, 1657-1663. [CrossRef]

12. Kaltenbrunner, M.; White, M.S.; Głowacki, E.D.; Sekitani, T.; Someya, T.; Sariciftci, N.S.; Bauer, S. Ultrathin and lightweight organic solar cells with high flexibility. Nat. Commun. 2012, 3, 770. [CrossRef]

13. Han, J.; Bao, F.; Huang, D.; Wang, X.; Yang, C.; Yang, R.; Jian, X.; Wang, J.; Bao, X.; Chu, J. A Universal Method to Enhance Flexibility and Stability of Organic Solar Cells by Constructing Insulating Matrices in Active Layers. Adv. Funct. Mater. 2020, 30, 2003654. [CrossRef]

14. Howarth, A.J.; Liu, Y.; Li, P.; Li, Z.; Wang, T.C.; Hupp, J.T.; Farha, O.K. Chemical, thermal and mechanical stabilities of metal-organic frameworks. Nat. Rev. Mater. 2016, 1, 15018. [CrossRef]

15. Zhou, K.; Xin, J.; Ma, W. Hierarchical Morphology Stability under Multiple Stresses in Organic Solar Cells. ACS Energy Lett. 2019, 4, 447-455. [CrossRef]

16. Zamani-Meymian, M.-R.; Sheikholeslami, S.; Fallah, M. Stability of Non-Flexible vs. Flexible Inverted Bulk-Heterojunction Organic Solar Cells with ZnO as Electron Transport Layer Prepared by a Sol-Gel Spin Coating Method. Surfaces 2020, 3, 319-327. [CrossRef]

17. Mousavi, S.L.; Jamali-Sheini, F.; Sabaeian, M.; Yousefi, R. Enhanced solar cell performance of P3HT:PCBM by SnS nanoparticles. Sol. Energy 2020, 199, 872-884. [CrossRef]

18. Krantz, J.; Stubhan, T.; Richter, M.; Spallek, S.; Litzov, I.; Matt, G.J.; Spiecker, E.; Brabec, C.J. Spray-Coated Silver Nanowires as Top Electrode Layer in Semitransparent P3HT:PCBM-Based Organic Solar Cell Devices. Adv. Funct. Mater. 2012, 23, 1711-1717. [CrossRef]

19. Liu, F.; Chen, D.; Wang, C.; Luo, K.; Gu, W.; Briseno, A.L.; Hsu, J.W.P.; Russell, T.P. Molecular Weight Dependence of the Morphology in P3HT:PCBM Solar Cells. ACS Appl. Mater. Interfaces 2014, 6, 19876-19887. [CrossRef] [PubMed]

20. Abdallaoui, M.; Sengouga, N.; Chala, A.; Meftah, A. Comparative study of conventional and inverted P3HT: PCBM organic solar cell. Opt. Mater. 2020, 105, 109916. [CrossRef]

21. Lee, J.; Liu, H.; Kang, J. A Study on an Organic Semiconductor-Based Indirect X-ray Detector with Cd-Free QDs for Sensitivity Improvement. Sensors 2020, 20, 6562. [CrossRef]

22. Bellani, S.; Najafi, L.; Capasso, A.; Castillo, A.E.D.R.; Antognazza, M.R.; Bonaccorso, F. Few-layer MoS 2 flakes as a hole-selective layer for solution-processed hybrid organic hydrogen-evolving photocathodes. J. Mater. Chem. A 2017, 5, 4384-4396. [CrossRef]

23. Li, S.; Ye, L.; Zhao, W.; Yan, H.; Yang, B.; Liu, D.; Li, W.; Ade, H.; Hou, J. A Wide Band Gap Polymer with a Deep Highest Occupied Molecular Orbital Level Enables 14.2\% Efficiency in Polymer Solar Cells. J. Am. Chem. Soc. 2018, 140, 7159-7167. [CrossRef]

24. Li, X.; Ma, R.; Liu, T.; Xiao, Y.; Chai, G.; Lu, X.; Yan, H.; Li, Y. Fine-tuning HOMO energy levels between PM6 and PBDB-T polymer donors via ternary copolymerization. Sci. China Ser. B Chem. 2020, 63, 1256-1261. [CrossRef]

25. Gloeckler, M.; Sankin, I.; Zhao, Z. CdTe Solar Cells at the Threshold to 20 Efficiency. IEEE J. Photovolt. 2013, 3, 1389-1393. [CrossRef]

26. Mariani, G.; Scofield, A.C.; Hung, C.-H.; Huffaker, D.L. GaAs nanopillar-array solar cells employing in situ surface passivation. Nat. Commun. 2013, 4, 1497. [CrossRef] [PubMed]

27. Zhang, Y.; Bartolo, R.E.; Kwon, S.J.; Dagenais, M. High Short-Circuit Current Density in CIS Solar Cells by a Simple Two-Step Selenization Process With a KF Postdeposition Treatment. IEEE J. Photovolt. 2016, 7, 1-8. [CrossRef] 
28. Mufti, N.; Amrillah, T.; Taufiq, A.; Sunaryono, A.; Diantoro, M.; Zulhadjri, N.H. Review of CIGS-based solar cells manufacturing by structural engineering. Sol. Energy 2020, 207, 1146-1157. [CrossRef]

29. Li, P.; Wu, B.; Yang, Y.C.; Huang, H.S.; De Yang, X.; Zhou, G.D.; Song, Q.L. Improved charge transport ability of polymer solar cells by using $\mathrm{NPB} / \mathrm{MoO}_{3}$ as anode buffer layer. Sol. Energy 2018, 170, 212-216. [CrossRef]

30. Sygletou, M.; Tzourmpakis, P.; Petridis, C.; Konios, D.; Fotakis, C.; Kymakis, E.; Stratakis, E. Laser induced nucleation of plasmonic nanoparticles on two-dimensional nanosheets for organic photovoltaics. J. Mater. Chem. A 2016, 4, $1020-1027$. [CrossRef]

31. Wu, W.; Wu, H.; Zhong, M.; Guo, S. Dual Role of Graphene Quantum Dots in Active Layer of Inverted Bulk Heterojunction Organic Photovoltaic Devices. ACS Omega 2019, 4, 16159-16165. [CrossRef] [PubMed]

32. Ahmad, R.; Srivastava, R.; Yadav, S.; Chand, S.; Sapra, S. Functionalized 2D-MoS2-incorporated polymer ternary solar cells: Role of nanosheet-induced long-range ordering of polymer chains on charge transport. ACS Appl. Mater. Interfaces 2017, 9 , 34111-34121. [CrossRef] [PubMed]

33. Ameri, T.; Khoram, P.; Min, J.; Brabec, C.J. Organic Ternary Solar Cells: A Review. Adv. Mater. 2013, 25, 4245-4266. [CrossRef]

34. Dwivedi, S.K.; Tiwari, D.; Tripathi, S.K.; Dwivedi, P.K.; Dipak, P.; Chandel, T.; Prasad, N.E. Fabrication and properties of P3HT: PCBM/Cu2SnSe3 (CTSe) nanocrystals based inverted hybrid solar cells. Sol. Energy 2019, 187, 167-174. [CrossRef]

35. Panwar, H.; Gupta, P.; Siddiqui, M.K.; Morales-Menendez, R.; Singh, V. Application of deep learning for fast detection of COVID-19 in X-Rays using nCOVnet. Chaos Solitons Fractals 2020, 138, 109944. [CrossRef]

36. Mathanker, S.K.; Weckler, P.R.; Bowser, T.J. X-Ray Applications in Food and Agriculture: A Review. Trans. ASABE 2013, 56, 1227-1239. [CrossRef]

37. Thomas, J.M. The birth of X-ray crystallography. Nature 2012, 491, 186-187. [CrossRef] [PubMed]

38. Woińska, M.; Grabowsky, S.; Dominiak, P.; Woźniak, K.; Jayatilaka, D. Hydrogen atoms can be located accurately and precisely by x-ray crystallography. Sci. Adv. 2016, 2, e1600192. [CrossRef]

39. Vikraman, D.; Liu, H.; Hussain, S.; Karuppasamy, K.; Youi, H.-K.; Jung, J.; Kang, J.; Kim, H.-S. Influence of morphological tuned nanostructure hybrid layers on efficient bulk heterojunction organic solar cell and X-ray detector performances. Appl. Surf. Sci. 2021, 543, 148863. [CrossRef]

40. Xu, Y.; Zhou, Q.; Huang, J.; Li, W.; Chen, J.; Wang, K. Highly-Sensitive Indirect-Conversion X-Ray Detector With an Embedded Photodiode Formed by a Three-Dimensional Dual-Gate Thin-Film Transistor. J. Light. Technol. 2020, 38, 3775-3780. [CrossRef]

41. Thirimanne, H.M.; Jayawardena, K.D.G.I.; Parnell, A.J.; Bandara, R.M.I.; Karalasingam, A.; Pani, S.; Huerdler, J.E.; Lidzey, D.G.; Tedde, S.F.; Nisbet, A.; et al. High sensitivity organic inorganic hybrid X-ray detectors with direct transduction and broadband response. Nat. Commun. 2018, 9, 1-10. [CrossRef] [PubMed]

42. Vikraman, D.; Hussain, S.; Rabani, I.; Feroze, A.; Ali, M.; Seo, Y.-S.; Chun, S.-H.; Jung, J.; Kim, H.-S. Engineering MoTe 2 and Janus SeMoTe nanosheet structures: First-principles roadmap and practical uses in hydrogen evolution reactions and symmetric supercapacitors. Nano Energy 2021, 87, 106161. [CrossRef]

43. Liu, H.; Hussain, S.; Ali, A.; Naqvi, B.A.; Vikraman, D.; Jeong, W.; Song, W.; An, K.-S.; Jung, J. A vertical WSe $2-$ MoSe $_{2}$ p-n heterostructure with tunable gate rectification. RSC Adv. 2018, 8, 25514-25518. [CrossRef]

44. Nguyen, D.A.; Oh, H.M.; Duong, N.T.; Bang, S.H.; Yoon, S.J.; Jeong, M.S. Highly Enhanced Photoresponsivity of a Monolayer $\mathrm{WSe}_{2}$ Photodetector with Nitrogen-Doped Graphene Quantum Dots. ACS Appl. Mater. Interfaces 2018, 10, 10322-10329. [CrossRef]

45. Ji, H.G.; Solís-Fernández, P.; Yoshimura, D.; Maruyama, M.; Endo, T.; Miyata, Y.; Okada, S.; Ago, H. Chemically Tuned p-and n-Type WSe 2 Monolayers with High Carrier Mobility for Advanced Electronics. Adv. Mater. 2019, 31, 1903613. [CrossRef]

46. Vikraman, D.; Hussain, S.; Patil, S.A.; Truong, L.; Arbab, A.A.; Jeong, S.H.; Chun, S.-H.; Jung, J.; Kim, H.-S. Engineering $\mathrm{MoSe}_{2} / \mathrm{WS}_{2}$ Hybrids to Replace the Scarce Platinum Electrode for Hydrogen Evolution Reactions and Dye-Sensitized Solar Cells ACS Appl. Mater. Interfaces 2021, 13, 5061-5072. [CrossRef]

47. Vikraman, D.; Akbar, K.; Hussain, S.; Yoo, G.; Jang, J.-Y.; Chun, S.-H.; Jung, J.; Park, H.J. Direct synthesis of thickness-tunable $\mathrm{MoS}_{2}$ quantum dot thin layers: Optical, structural and electrical properties and their application to hydrogen evolution. Nano Energy 2017, 35, 101-114. [CrossRef]

48. Su, Y.-W.; Lin, Y.-C.; Wei, K.-H. Evolving molecular architectures of donor-acceptor conjugated polymers for photovoltaic applications: From one-dimensional to branched to two-dimensional structures. J. Mater. Chem. A 2017, 5, 24051-24075. [CrossRef]

49. Liu, H.; Hussain, S.; Kang, J. Improvement in sensitivity of an indirect-type organic X-ray detector using an amorphous IGZO interfacial layer. J. Instrum. 2020, 15, P02002. [CrossRef]

50. Zhang, B.; Chen, T. Study of Ultrasonic Dispersion of Graphene Nanoplatelets. Materials 2019, 12, 1757. [CrossRef]

51. Hussain, S.; Patil, S.A.; Vikraman, D.; Arbab, A.A.; Jeong, S.H.; Kim, H.-S.; Jung, J. Growth of a WSe $2 /$ W counter electrode by sputtering and selenization annealing for high-efficiency dye-sensitized solar cells. Appl. Surf. Sci. 2017, 406, 84-90. [CrossRef]

52. Li, H.; Lu, G.; Wang, Y.; Yin, Z.; Cong, C.; He, Q.; Wang, L.; Ding, F.; Yu, T.; Zhang, H. Mechanical exfoliation and characterization of single-and few-layer nanosheets of $\mathrm{WSe}_{2}, \mathrm{TaS}_{2}$, and TaSe 2 . Small 2013, 9, 1974-1981. [CrossRef] [PubMed]

53. Hussain, S.; Akbar, K.; Vikraman, D.; Afzal, R.A.; Song, W.; An, K.-S.; Farooq, A.; Park, J.-Y.; Chun, S.-H.; Jung, J. WS $(1-x) S_{x}$ Nanoparticles Decorated Three-Dimensional Graphene on Nickel Foam: A Robust and Highly Efficient Electrocatalyst for the Hydrogen Evolution Reaction. Nanomaterials 2018, 8, 929. [CrossRef] 
54. Panigrahi, P.K.; Pathak, A. A novel route for the synthesis of nanotubes and fullerene-like nanostructures of molybdenum disulfide. Mater. Res. Bull. 2011, 46, 2240-2246. [CrossRef]

55. Tan, X.; Kang, W.; Liu, J.; Zhang, C. Synergistic Exfoliation of $\mathrm{MoS}_{2}$ by Ultrasound Sonication in a Supercritical Fluid Based Complex Solvent. Nanoscale Res. Lett. 2019, 14, 1-7. [CrossRef] [PubMed]

56. Kakavelakis, G.; Castillo, A.E.D.R.; Pellegrini, V.; Ansaldo, A.; Tzourmpakis, P.; Brescia, R.; Prato, M.; Stratakis, E.; Kymakis, E.; Bonaccorso, F. Size-Tuning of WSe ${ }_{2}$ Flakes for High Efficiency Inverted Organic Solar Cells. ACS Nano 2017, 11, 3517-3531. [CrossRef] [PubMed] 